\title{
Short-term decisions in lake restoration have long-term consequences for water quality
}

\author{
Romina Martin ${ }^{1}$ - Sonja Radosavljevic ${ }^{1}$. Maja Schlüter ${ }^{1}$
}

Received: 16 April 2019 / Accepted: 10 April 2020 / Published online: 17 August 2020

(C) The Author(s) 2020

\begin{abstract}
Ecological regime shifts from clear to turbid water states in shallow temperate lakes are quite well-investigated phenomena but critical time lags from human interaction with the lake and restoration activities are much less understood. This is a complex challenge for institutions who manage lakes but are usually less familiar with non-linear dynamics, slow and fast influences on water quality and how to manage those from a social-ecological perspective. We extend a well-known minimal model of shallow lake regime shifts to enable simulations over time with short- and long-term management measures (nutrient reduction, trawling, planting of aquatic vegetation). While we explore the mathematical conditions for ecological bistability, we also identify the necessary and sufficient extent of measures to restore the clear water state. Restoration scenarios evaluated by trajectories in the state space demonstrate the increased effectiveness from combined measures even when considering countereffective activities such as pike fishing. But, single measures alone may delay or even miss the overall restoration target. Our analysis demonstrates the importance of understanding transient dynamics where stable state analyses alone remain elusive about alternative ways to interact with bistability. We conclude that successful management of bistable systems, and particularly shallow temperate lakes, needs careful balancing between short-term improvements and long-term influence on the systems state.
\end{abstract}

Keywords Bistability $\cdot$ Shallow temperate lakes $\cdot$ Stylised model $\cdot$ Social-ecological system $\cdot$ Restoration

\section{Introduction}

Large-scale, persistent and often unexpected changes in a system are referred to as regime shifts (Scheffer et al. 2001). Ecological regime shifts are a prominent phenomenon occurring in different ecosystems with negative implications for human well-being and the sustainability of socialecological systems (Biggs et al. 2018; Rocha et al. 2015; Gunderson et al. 2006). While the ecological feedbacks

This article is part of the Topical Collection in Sustainability of social-ecological systems

Electronic supplementary material The online version of this article (https://doi.org/10.1007/s10113-020-01643-4) contains supplementary material, which is available to authorized users.

Romina Martin

romina.martin@su.se

1 Stockholm Resilience Centre, Stockholm University, Kräftriket 2B, Stockholm, 10691, Sweden that characterise different regimes and shifts between them are quite well understood in many systems, the social dynamics of interactions of people and institutions are much less known (Lade et al. 2013). For shallow lakes, for instance, several mathematical models exist to investigate regime shift dynamics between clear and turbid water states (Mooij et al. 2009; Beisner et al. 2003; Scheffer 1990). The purpose of these models is mainly to identify the values of the driver, usually nutrient concentration, at which a small change causes a large difference in the response (tipping point). They, however, often do not explore alternative measures how humans could manage such a bistable system over time, even after a tipping point to the undesirable state was transgressed. Shallow temperate lakes are the only system among freshwaters so far with empirical evidence for regime shifts happening between multiple stable states (Capon et al. 2015). Here, we explore alternative management responses to a shallow lake in the turbid water state and measures which support the restoration to improve water quality and therewith human well-being. 
Humans interact with and benefit in multiple ways from good water quality in freshwaters but at the same time affect it adversely through intensive agriculture and urbanisation. In most shallow temperate lakes, the accumulation of nutrients in the water column and sediments is the main driver for the shift towards the turbid water state (Scheffer et al. 1993), which has been the most serious environmental threat to lakes in the temperate zone over the last century (Jeppesen et al. 2007). Management measures thus often addressed the nutrient sources such as over-fertilization in agriculture or insufficient urban wastewater treatment (Jeppesen et al. 2007). Insufficient wastewater treatment by municipal and private systems is, for instance, contributing considerably to the eutrophication in the Baltic region (Wallin et al. 2013). Multiple measures have been tested for restoring lakes that have shifted into a turbid state (Mehner et al. 2004; Carpenter et al. 2001). Measures range from slow, long-term processes (relatively to lake restoration time) of nutrient load reduction or wetland construction, to short- and mid-term by directly interfering with lakeinhabiting species (biomanipulation by catching whitefish, stocking predatory fish or planting aquatic vegetation; Jeppesen et al. (2007)). Social dynamics in policy making and implementation can significantly delay and therewith change the effectiveness of restoration measures (Martin et al. 2020). That is why, often, a combination of measures is advisable to accelerate lake restoration but these combinations are so far rarely investigated.

Long-term measures which address slow variables are particularly relevant for the management of regime shifts because those variables slowly move the system towards the tipping point to the undesired regime (Biggs et al. 2018; Hughes et al. 2013). An example of a slow variable in lakes is the accumulation of nutrients in sediments. This slow process of accumulation is challenging to manage due to widely distributed and often diffuse sources (agriculture, wastewater treatment; Carpenter et al. (1998)), a mismatch between the scale at which the ecosystem operates and at which it is managed (Kininmonth et al. 2015), and conflicting interests among largely disconnected actors (Galaz 2005; Pahl-Wostl et al. 2012). Slow variables often remain unnoticed until it is too late which emphasises the need for timely management to monitor, understand and manage the dominant, long-term drivers in a system. Managing social-ecological systems characterised by processes at different temporal and spatial scales requires improved understanding of the dynamics of bistable systems (Martin et al. 2020), i.e. systems that can exhibit two different regimes for the same value of the slow variable. This is important because long-term measures may create a landscape of possible outcomes, such as two alternative regimes in bistable systems (Table 1), while short-term measures can steer the system relatively fast towards the desired outcome.

Lake research has developed a range of empirically motivated and theoretical models to better understand and guide shallow lake management (Mooij et al. 2009). Simpler models were developed for the purpose of explaining multiple origins of bistability in lake ecosystems (Scheffer 1990) and analysing empirical bimodal data (Beisner et al. 2003). While the analysis of tipping points, early-warning signals (Dakos et al. 2014; Contamin and Ellison 2009) and underlying feedbacks causing equilibrium dynamics received plenty of attention (Scheffer et al. 2001), the analysis of transient dynamics with short- and long-term implications for managing a lake was much less explored. This is particularly relevant when accounting for time lags caused by delayed or slow human responses to an ongoing regime shift (Martin and Schlüter 2015; Martin et al. 2020), as well as the effects of simultaneous, counter-effective activities (fishing) or shifting baselines (climate change) (Selkoe et al. 2015; Duarte et al. 2009). Modelling regime shifts to understand their transient dynamics and how management may interact with them can be achieved from a theoretical perspective through the analysis of bistability. Bifurcation analysis is one method to identify zones of bistability and how they are defined by tipping points (Ashwin et al. 2012). Only few examples exist so far which analyse social dynamics as explicit as the ecological ones. For example, causal loop diagrams and dynamical systems theory can help explain the origin of tipping points and the corresponding processes driving regime shifts (Lade et al. 2015). Here, we aim to take a step in this direction by investigating the time needed for lake restoration as an outcome of one or multiple restoration measures. To this end, we extend a model of shallow lake bistability (Scheffer 1989) to examine the effect of measures for lake restoration which operate at different time scales. As a novel contribution, we investigate dynamics of a 3-dimensional model which allows us to study interlinked dynamics of bream, pike and vegetation impacted by different short- and long-term measures. Our study helps better understand the effectiveness of different (combined) restoration measures in shallow lakes by evaluating simulations in a socialecological context while exploring the following questions:

- What can we learn from analyses of ecological bistability about the implications of different management interventions, i.e. short-term or long-term technical measures for lake restoration?

- How does a combination of measures accelerate restoration compared with single or short-term measures?

We present in the following the model design and explain how it is suitable to analyse the effects from short- 
and long-term restoration measures. The results show an analysis of equilibrium points and long-term system dynamics, bifurcation analysis and robustness analysis of the extended model and explore scenarios of different combinations of restoration measures. We conclude by discussing insights and limitations from model design, analysis and implications for managing bistable systems.

\section{Methods}

A minimal model to describe bistability in shallow lakes was developed by Scheffer (1989), hereafter called $M_{0}$. It consists of two differential equations for the predator-prey relationship between two fish species (pike, Esox Lucius; bream, Abramis Brama), while the density of submerged vegetation is represented as a function of bream. This model formulation allows studying the effects that bream and

Table 1 Glossary of terms, adapted from Kuznetsov (2004)

\begin{tabular}{|c|c|}
\hline Term & Description \\
\hline State space & $\begin{array}{l}\text { Space of all possible configura- } \\
\text { tions or states of a dynamical } \\
\text { system. }\end{array}$ \\
\hline Equilibrium point & $\begin{array}{l}\text { A state of a dynamical system at } \\
\text { which the system will stay if it } \\
\text { starts from that point. }\end{array}$ \\
\hline Trajectory & $\begin{array}{l}\text { A time-ordered set of states of a } \\
\text { dynamical system that originate } \\
\text { from an initial state following } \\
\text { rule of evolution. }\end{array}$ \\
\hline Attractor & $\begin{array}{l}\text { A state (or set of states) of a } \\
\text { dynamical system to which tra- } \\
\text { jectories originating from initial } \\
\text { conditions converge over time. }\end{array}$ \\
\hline Basin of attraction & $\begin{array}{l}\text { For each attractor, its basin of } \\
\text { attraction is the set of initial states } \\
\text { leading to long-time behaviour } \\
\text { that approaches that attractor. }\end{array}$ \\
\hline Stability & $\begin{array}{l}\text { A property of a system to return } \\
\text { to an attractor after perturbations. }\end{array}$ \\
\hline Bistable system (bistability) & $\begin{array}{l}\text { A dynamical system that has } \\
\text { two attractors. Depending on the } \\
\text { initial conditions, future states of } \\
\text { the system tend to one of the two } \\
\text { attractors. }\end{array}$ \\
\hline Bifurcation & $\begin{array}{l}\text { A qualitative change in sys- } \\
\text { tem's dynamics as one (or more) } \\
\text { parameter is varied. }\end{array}$ \\
\hline Tipping points & $\begin{array}{l}\text { Discontinuities between current } \\
\text { and future states of the system } \\
\text { when small perturbations in the } \\
\text { driver variable around the tipping } \\
\text { point cause large changes in the } \\
\text { response variable. }\end{array}$ \\
\hline
\end{tabular}

pike may have on the lakes' system dynamics. Since the vegetation in $M_{0}$ is not described by an independent state variable but is directly related to the density of bream, the model does not incorporate properties of submerged vegetation and their contribution to the lake's system dynamics. In this way, model $M_{0}$ cannot assess effects of certain types of regulation (such as bream trawling or vegetation planting, Fig. 1) on lake restoration.

To better understand dynamical implications from socialecological interactions in lake restoration, more specifically, how measures affect a shift towards the clear state, we extend the minimal system dynamics model $M_{0}$ (Fig. 1) by introducing vegetation as additional state variable. In Section "Model formulation", we present assumptions and formulation of the extended model. In Section "Model analyses", we briefly explain different approaches for the analysis of the model and highlight short- and long-term measures aiming to restore the clear water state, as well as human activities which reinforce or delay the restoration.

\section{Model formulation}

$M_{0}$ has several underlying assumptions which are supported by empirical evidence:

$A_{1} \quad$ Bream reproduction is greater in nutrient-enriched waters.

$A_{2}$ High bream densities limit the development of aquatic vegetation.

$A_{3}$ Pike is a predator of bream.

$A_{4}$ Pike reproduction requires aquatic vegetation.

In order to incorporate vegetation as a state variable, we introduced another assumption along with the basic ones:

$A_{5}$ The mortality of aquatic vegetation is mainly driven by the density of bream but its recovery is driven by its intrinsic growth rate.

Using assumptions $A_{1}-A_{5}$ and bream $B$, pike $P$ and vegetation $V$ as state variables, we extend model $M_{0}$ and formulate model $M_{1}$ as follows:

$$
\begin{aligned}
\frac{d B}{d t} & =r_{B} \frac{N}{N+H_{1}} B-c_{B} B^{2}-p_{r} \frac{P B^{2}}{H_{4}^{2}+B^{2}}+i_{B}, \\
\frac{d P}{d t} & =p_{r} p_{e} \frac{B^{2} P}{H_{4}^{2}+B^{2}} \frac{V}{H_{2}+V}-c_{P} P^{2}-m_{P} P+i_{P}, \\
\frac{d V}{d t} & =r_{V} V-c_{V} V^{2}-m_{V} \frac{V B^{2}}{H_{3}^{2}+B^{2}} .
\end{aligned}
$$

The first and the second equations in model $M_{1}$ define the rate of change in bream and pike through logistic 


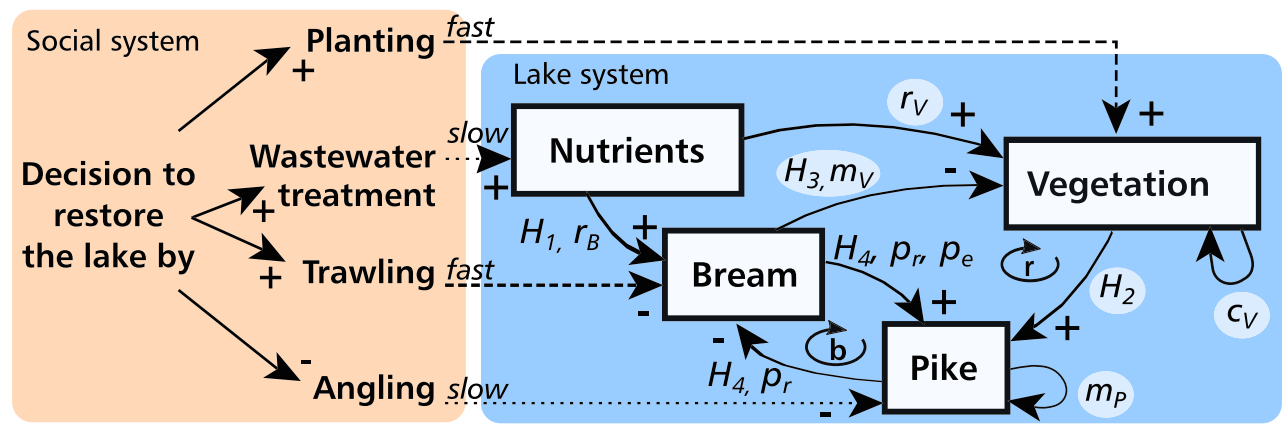

Fig. 1 Four regulation measures are explored in their single and combined effects on lake restoration time. Dashed lines indicate how fast or slow the measures change the stocks relatively to lake restoration time. The lake's main components are shown by a causal loop diagram depicting the feedbacks from the original model including their parameters (Scheffer 1989) and our additions (highlighted) to enable independent manipulation of all state variables. " $r$ " denotes the reinforcing loop, while "b" denotes the balancing loop growth and predator-prey relations. Assumption $A_{1}$ implies that the growth rate of bream is a function of nutrients (hence the term $\frac{N}{N+H_{1}}$ ), while assumption $A_{3}$ leads to the pike-dependent mortality of bream (represented by $\frac{P B^{2}}{H_{4}^{2}+B^{2}}$ ). Assumptions $A_{3}$ and $A_{4}$ imply that the growth rate of pike depends on bream and vegetation, which is reflected in the term $\frac{B^{2}}{H_{4}^{2}+B^{2}} \frac{V}{H_{2}+V}$. The pike mortality rate due to fishing is given by the term $-m_{P} P$ and immigration rates for bream and pike are $i_{B}$ and $i_{P}$, respectively. These two equations correspond to model $M_{0}$.

The third equation defines the rate of change for vegetation through vegetation growth (modelled as a logistic growth represented by $r_{V} V-c_{V} V^{2}$ ) and vegetation mortality due to bream (given by $m_{V} \frac{V B^{2}}{H_{3}^{2}+B^{2}}$ ). According to assumption $A_{5}$, the relation between vegetation and bream is one-sided: bream is detrimental to vegetation, but vegetation has no effect on bream. Because of this asymmetry, we assume that bream density determines the strength of bream-vegetation interaction. Bream has a weak negative effect on vegetation when its density is low, but this effect increases as bream density grows and finally levels off for high density of bream. We model this relation using the Holling type III response with bream as a variable.

Parameter definition and values are in Table 1 in the Online Resource (S1). To respect both the assumptions for $M_{0}$ and $M_{1}$ and maintain the basic, reversible bistability of the lake system, several alternative formulations were tested and parameters were calibrated.

From the mathematical perspective, model $M_{1}$ is a 3 dimensional nonlinear system. Nonlinearity makes such systems difficult, if not impossible, to solve analytically, but it is possible to investigate behaviour of solutions using stability and bifurcation analyses. We rely on numerical methods to conduct these analyses.

\section{Model analyses}

Dynamics between aquatic vegetation, bream and pike under change of nutrient concentration is defined by model $M_{1}$. We make a distinction between two types of measures: (1) long-term measures, i.e. measures that are changing relations between interacting species by changing a parameter value or the functional form and consequently change the dynamics of the system; and (2) short-term measures, i.e. measures that are not influencing the dynamics of the system, but rather act quickly and change the initial conditions. As an example of a longterm measure, we point out pike fishing which increases pike mortality rate. Short-term examples are vegetation planting or bream trawling because these measures take a significantly shorter time to complete in comparison to time needed for their effect to take place. In other words, the short-term measure is a means to change the initial state of the system. Because of this dichotomy, the analysis of model $M_{1}$ is based on the analysis of the state space (for tracking long-term dynamics), bifurcation analysis and changes in trajectories resulting from different measures (for investigating transient behaviour from different initial states). By combining several types of analyses, we aim to disclose properties of the system dynamics and possibilities for designing restoration measures.

Meaning of the state space in shallow lake models In shallow lakes, an attractor corresponds to the clear state if its aquatic vegetation dominates and reinforces a relatively low level of bream (Carpenter et al. 2001). Conversely, an attractor corresponds to the turbid state if the bream population dominates and destroys large parts of the vegetation. Functional forms in differential equations in $M_{1}$ together with parameter values influence the number and 
Table 2 Results of bifurcation analysis with $N$ as a bifurcation parameter and $m_{V}=0.007$ under variation of $c_{V}$ (top) and $c_{V}=0.00006$ under variation of $m_{V}$ (below)

\begin{tabular}{|c|c|c|c|c|c|}
\hline$c_{c_{V}\left(10^{-5}\right)}^{r_{V}\left(10^{-3}\right)}$ & 4 & 5 & 6 & 7 & 8 \\
\hline 4 & $\mathrm{~T}$ & $\mathrm{~T}$ & $\mathrm{BI}(N>0.28)$ & $\mathrm{C}$ & $\mathrm{C}$ \\
\hline 5 & $\mathrm{~T}$ & $\mathrm{~T}$ & $\mathrm{BI}(N>0.26)$ & $\mathrm{BI}(N>0.89)$ & $\mathrm{C}$ \\
\hline 6 & $\mathrm{~T}$ & $\mathrm{~T}$ & $\mathrm{~B}(N \in[0.24,1.4])$ & BI $(N>0.7)$ & $\mathrm{C}$ \\
\hline 7 & $\mathrm{~T}$ & $\mathrm{~T}$ & $\mathrm{~B}(N \in[0.23,0.83])$ & $\mathrm{BI}(N>0.57)$ & $\mathrm{C}$ \\
\hline 8 & $\mathrm{~T}$ & $\mathrm{~T}$ & $\mathrm{~T}$ & $\mathrm{~B}(N \in[0.49,2.65])$ & $\mathrm{C}$ \\
\hline \multicolumn{6}{|l|}{$m_{V}\left(\cdot 10^{-3}\right)$} \\
\hline 4 & $\mathrm{~T}$ & $\mathrm{C}$ & $\mathrm{C}$ & $\mathrm{C}$ & $\mathrm{C}$ \\
\hline 5 & $\mathrm{~T}$ & B $(N \in[0.46,2.06])$ & $\mathrm{C}$ & $\mathrm{C}$ & $\mathrm{C}$ \\
\hline 6 & $\mathrm{~T}$ & $\mathrm{~T}$ & $\mathrm{BI}(N>0.57)$ & $\mathrm{C}$ & $\mathrm{C}$ \\
\hline 7 & $\mathrm{~T}$ & $\mathrm{~T}$ & $\mathrm{~B}(N \in[0.24,1.4])$ & $\mathrm{BI}(N>0.7)$ & $\mathrm{C}$ \\
\hline 8 & $\mathrm{~T}$ & $\mathrm{~T}$ & $\mathrm{~B}(N \in[0.17,0.6])$ & $\mathrm{BI}(N>0.28)$ & $\mathrm{BI}(N>0.83)$ \\
\hline
\end{tabular}

Abbreviations: $T$, single turbid attractor; $C$, single clear attractor; $B I$, imperfect bistability, i.e. one tipping point and hysteresis for low nutrient concentration but no hysteresis for high nutrient concentration; $B$, bistability with two tipping points with hysteresis. Interval of nutrient concentration for which bistability is possible is in brackets. The bold entry denotes our chosen baseline setting

position of attractors as well as the shape of their basins of attraction.

Bifurcation analysis and parameter variation Model $M_{1}$ tracks changes in three state variables, $B, P$ and $V$, for a certain range of parameters. Since parameters can change (for example due to restoration efforts to reduce nutrient load) or they vary for different species, we study effects of parameter variation on the dynamic behaviour of the system. Bifurcation diagrams show changes in number, position and type of equilibrium points caused by changes in the driving parameter. We use the nutrient concentration $N$ as the driving parameter to explore how bistability responds to different values for vegetation reproduction, intraspecific competition and mortality rate $\left(r_{V}, c_{V}\right.$ and $m_{v}$, respectively, specified in Online Resources S1 Table 2).

Trajectories and short-term measures Starting from an initial state, the system evolves following the dynamics defined by model $M_{1}$ and given sufficient time it reaches an attractor. Plotting trajectories in the state space reveals the transient dynamics of the system. We use trajectories to measure time intervals from different initial states applying

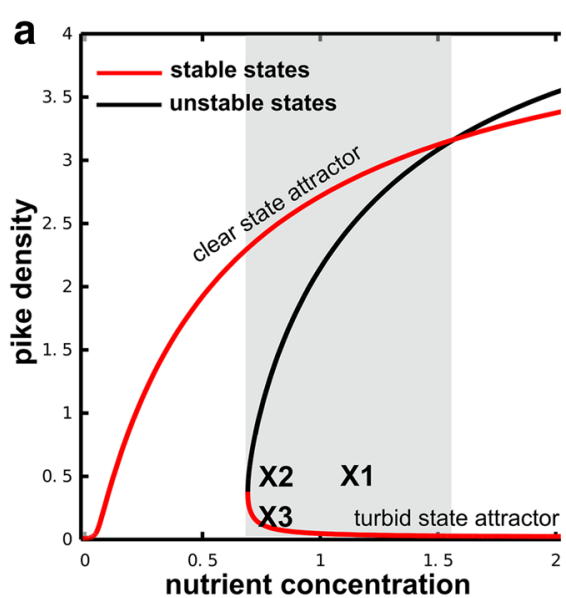

Fig. 2 Bifurcation analysis for a pike, $\mathbf{b}$ bream and $\mathbf{c}$ vegetation density. The grey area denotes the bistable space explored in this analysis. The bifurcation diagrams illustrate a case of imperfect bifurcation for
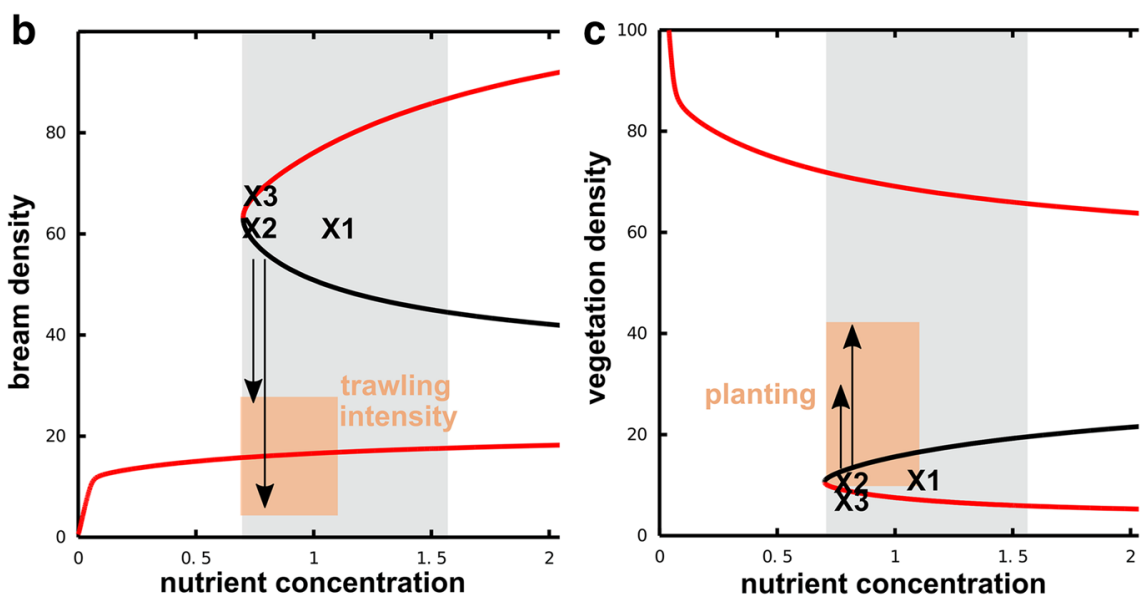

nutrient concentrations greater than 1.6. The initial states for our experiments are shown by $X 1, X 2$ and $X 3$, and linked to intensity ranges for short-term restoration measures depicted by the orange rectangles 
long-term management measures to when they reach the stable clear state and compare their effectiveness.

Short-term measures, on the other hand, are changing initial conditions, but they are not changing the dynamics of the system. They can cause a shift from one basin of attraction to another and, by doing this, change the outcome. We study effects of combination of short- and long-term measures by combining the change in initial conditions with a change in dynamics (Fig. 2).

Assumptions for social-ecological activities Despite the widespread recognition of multiple benefits from clear water and increased costs with turbid water (Carpenter et al. 1998), policy making for and implementation of upgrading sewage treatment systems show considerable time lags in lake restoration processes. This was explored in an earlier social-ecological simulation model of lake restoration to identify the magnitude for time lags from regulation and policy implementation compared with ecological feedbacks in the lake (Martin et al. 2020). Assuming that restoration will only be triggered after detrimental effects from abundant nutrients are visible on all trophic levels (e.g. by decreasing pike populations), the adaptive responses for regulation and implementation of upgraded sewage systems by private households were estimated under different social reinforcement scenarios. Scenario simulations resulted in a restoration delay between 10 and 30 years under which the nutrient concentration was reduced between 50 and $80 \%$. We use the simulation results as initial condition here to account for different long-term restoration measures (such as nutrient reduction and pike fishing) in response to lake eutrophication (Online Resources S1, Table 2).
We explore other more short-term responses which are prominent restoration measures and consider biomanipulation in the form of reducing bream through high-intensity trawling and the planting of submerged vegetation (Jeppesen et al. 2007). Since not all human activities at lakes target lake restoration, we also study the adverse effects from pike angling during the restoration period.

Experimental setup to explore options and risks for lake restoration The baseline parameter set of $M_{1}$ was used to analyse the stable states in response to changed nutrient conditions in bifurcation analyses. While the original model $\left(M_{0}\right)$ showed two tipping points delimiting the range for hysteresis behaviour, the number of tipping points for $M_{1}$ depends on several parameter choices and the system may have zero, one or two tipping points. Since we want to study the transition from the turbid to the clear state, we choose model parameter values which allow the existence of at least one tipping point and fulfil the main properties from $M_{0}$.

Through bifurcation analysis, one can identify the trivial solution to long-term restoration which would be a nutrient reduction below the tipping point. We are interested, however, to explore non-trivial trajectories to restoration for bistable systems which are in transition between stable states (Fig. 2). For these restoration trajectories, single measures as trawling or planting vegetation or their combination are explored from different initial conditions. The initial conditions $X 1, X 2$ and $X 3$ are extreme examples based on different time lags from regulation and intensities of wastewater treatment (Online Resources S1 Table 2, Martin et al. (2020)). X1 represents a state from a minimal regulation time lag and an average wastewater treatment.
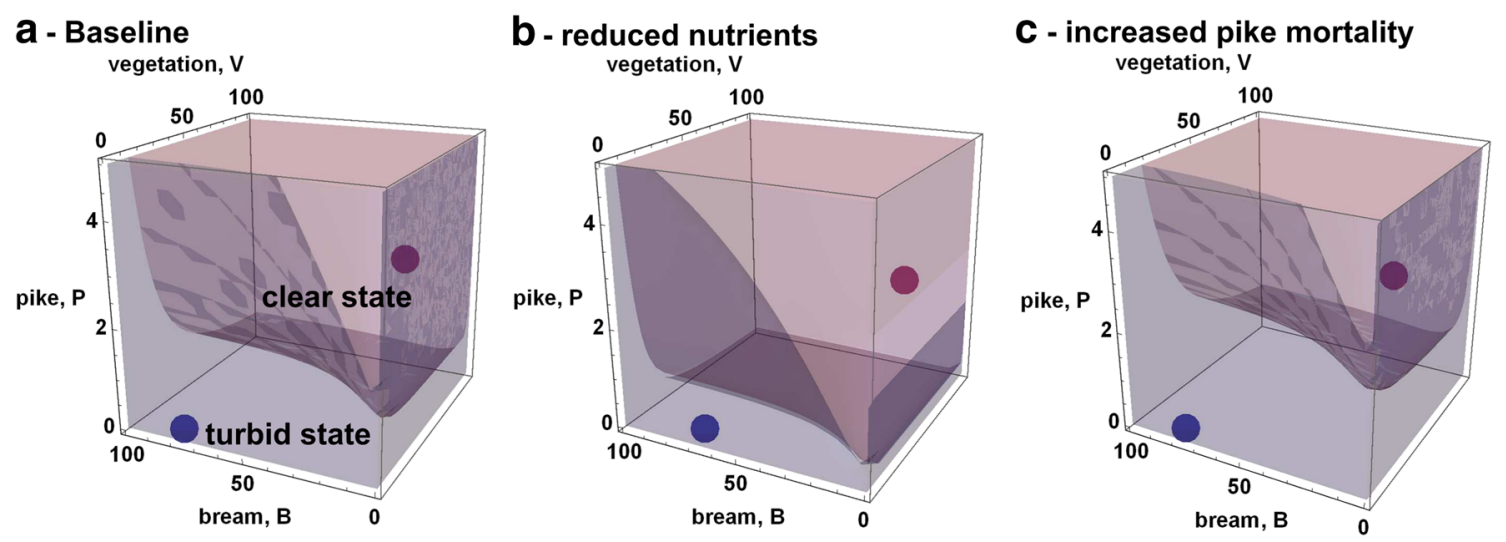

Fig. 3 Attractors and basins of attraction for model $\left(M_{1}\right)$ are represented by blue and purple dots and corresponding coloured volumes. Used parameter values are $r_{V}=7 \cdot 10^{-3} \mathrm{day}^{-1}, c_{V}=6 \cdot 10^{-5} \mathrm{~m}^{2}$,

$m_{V}=7 \cdot 10^{-3}$ day $^{-1}, H_{2}=20 . \mathbf{a} N=1.125$ and coordinates of turbid state (the blue disc) are $(79.6,0.038,6.91)$ and of clear state (the purple disc) are $(16.92,2.86,67.97)$. b $N=0.8$. c $m_{P}=2.475$. $10^{-4}$ day $^{-1}$ 
$X 2$ assumes an improved acceleration of nutrient reduction. $X 3$ represents a state after experiencing the maximum regulation time lag.

\section{Results}

\section{State spaces, equilibrium points and system dynamics}

Figure 3 shows the position of attractors and shapes of basins of attraction for the baseline parameter set (Online Resource S1, Table 1). It allows investigation of consequences of various short-term measures for lake dynamics, as well as outcomes of combinations of long- and short-term measures.

The shape of the clear basin of attraction and the position of the clear attractor suggests that the system in a clear state and near the clear equilibrium is more resilient to changes in vegetation and bream than to decreases in pike density. A sufficiently large decrease of pike density can push the system from the clear basin of attraction into the turbid basin of attraction. With greater values for bream density, greater pike and vegetation values are needed for keeping the system in the clear state.

From the turbid state perspective, there exists a threshold of pike density which is necessary for reaching the clear basin of attraction. This threshold value decreases in less nutrient-rich water (Fig. 3b), but it increases with increased pike mortality, due to fishing for example (Fig. 3c). If the pike density is above the threshold value, reducing the bream density may be sufficient for pushing the system into the clear basin of attraction. Otherwise, increasing pike density becomes a necessary measure for restoration.

Decreasing the nutrient concentration and increasing pike mortality are countereffective to each other in terms of the resulting system dynamics. This can be seen by comparing the volumes of turbid basins of attraction in Fig. $3 b$ and c. Combining these two measures can help balance system dynamics and keep the pike density threshold value low even under increased mortality due to fishing (Fig. 2b in Online Resources S2).

Properties of vegetation affect the shape of basins of attraction. The increased half-saturation constant $\mathrm{H}_{2}$, i.e. increased vegetation density needed for pike reproduction, leads to higher pike threshold values needed for reaching the clear state (compare Fig. 3a and Fig. 2a in Online Resources $\mathrm{S} 2$ ).

\section{Bifurcation analyses show sensitivity of bistability to vegetation parameter variations}

We explore a range of suitable values for the newly introduced parameters defining vegetation properties to better understand their effect on bistability in the system. Bistability is evaluated through bifurcation diagrams with nutrient concentration $N$ as a bifurcation parameter. For our choice of baseline parameter values, we get a case of imperfect bifurcation, i.e. a case of a bistable system without hysteresis (Fig. 2a). Although this case is unsuitable to explore the process of eutrophication $(N \geq 1.5)$, the attractor shapes for values $N \leq 1.5$ are sufficiently similar to the original model $M_{0}$.

To study effects of change in nutrient concentration in lakes with different vegetation types, we expand the bifurcation analysis with $N$ as a bifurcation parameter for several combinations of parameter values in $r_{V}, c_{V}$ and $m_{V}$ and present results in Table 2 and in Online Resources S3.

The upper part of Table 2 shows combinations of the vegetation growth rates and intraspecific competition for a constant mortality rate, while in the lower part, we vary mortality rates and keep the intraspecific competition constant. Given a low vegetation growth rate $\left(r_{V} \leq 0.005\right)$, the system remains in a turbid state for all choices of intraspecific competition $c_{V}$ and almost all choices of bream-induced mortality. For a high vegetation growth rate $\left(r_{V}=0.008\right)$, intraspecific competition has no effect on the stability of the system and it remains in a clear state, but high mortality $\left(m_{V}=0.008\right)$ can cause bistability. For medium vegetation growth rates $\left(r_{V}=0.006\right.$ or $\left.r_{V}=0.007\right)$, increasing the intraspecific competition $c_{V}$ or increasing the mortality rate $m_{V}$ reduces the interval of bistability and may cause a shift from a unique clear stable state to bistability or from bistability to turbid state. At the same time, the unstable states between the clear and turbid attractor move closer to the clear attractor making it less resilient as in the example shown for pike density (Online Resource, S3, Fig. 4). The lake system $\left(M_{1}\right)$ is more sensitive to changes in vegetation growth and mortality than to intraspecific competition.

Figure 5 in Online Resources shows comparison of bifurcation diagrams where vegetation mortality or intraspecific competition is varied but the growth rate is kept constant. It is evident that the nutrient concentration can lead to different outcomes for various types of aquatic vegetation. The interval of nutrient concentration for which the clear state is possible becomes shorter for higher values of vegetation mortality. In contrast to this, the interval of nutrient concentration is wider for higher vegetation 
mortality rates. Whereas the clear state attractor is quite robust for pike against most variations in intraspecific competition, the unstable and turbid states are not. Namely, the turbid state is possible for lower nutrient concentrations when intraspecific competition rate increases.

\section{Trajectories to reach the clear state with short-term measures}

Trajectory simulations of the system in state space enable us to evaluate the outcome of a measure, particularly with what speed a system will evolve towards the clear state from a specific initial condition. Due to the nonlinear behaviour of the system, the visual proximity to the nearest stable state is insufficient to predict the time to reach it.

Table 3 shows the attainment of and duration for reaching the clear water state from combinations of short-term measures which placed the system on different initial states. We compare two measures: an increase in vegetation through planting indicated by increasing numbers of vegetation density, and a decrease in bream through trawling indicated by decreasing numbers of bream density. For example, if we start from the initial state of $\mathrm{X} 1$, introduced in Fig. 2, only a combination of very radical short-term measures such as a reduction of bream by at least $66 \%$ and and an increase of vegetation by $750 \%$ through planting would result in a clear state. Assuming an initial state resulting from a slightly more efficient nutrient reduction, as depicted by $\mathrm{X} 2$, provides the most promising perspective for successful short-term measures. The more the bream population is reduced and at the same time vegetation increased, the shorter is the time to reach the clear state. However, the response of the system to these measures is initially very slow. Short-term measures of a vegetation increase and bream decrease towards $V=15$ and $B=20$, respectively, result in very long restoration times. However, a slight increase in both measures can here reduce the overall restoration time by more than two-thirds.
Table 3 also shows that for some initial conditions even a single measure, such as bream reduction or vegetation planting, can be sufficient to reach the clear state. However, comparing results for a single measure (blue entries) with the result for combined measures (the red entry), we come to the conclusion that combined application of measures reduces the restoration time in this case by more than half.

Within the same range of short-term measures but starting with $\mathrm{X} 3$ for pike density after a delayed nutrient reduction (Fig. 2), only the most intense applications of bream reduction $(-75 \%)$ and planting $(+150 \%)$ result in a clear state after approximately 30 years (Online Resources S4, Table 2). This experiment shows that detrimental initial conditions for pike can be better compensated by vegetation planting than by bream reduction.

In a similar way is pike fishing (here represented as a continuous, i.e. long-term activity) a challenge for finding suitable restoration measures. Under these conditions, the system dynamics are changed fundamentally by increasing the threshold for the pike and vegetation density necessary for reaching the clear state (Online Resource, S4, Table 3). Here, planting measures need to be even stronger in order to plan for a successful restoration.

In summary, the more unfavourable the lake conditions are at the onset of short-term measures, for instance because the implementation of regulations for nutrient reductions is slow, the stronger or more radical restoration measures are necessary to reach the clear water state (Table 4). Vegetation planting was the most efficient single measure under initial conditions (except for X1) that are relatively close to the tipping point towards the clear state. For systems that are more distant from the tipping point, a combination of restoration measures is required. Long-term changes to the system dynamics, such as those resulting from increased pike mortality, are, however, likely to more strongly influence restoration time than short-term responses.

Table 3 Rounded time (in years) for reaching the clear state when applying short-term measures (targeted density values for bream reduction and/or vegetation planting) when starting from the initial system conditions with $N=0.8$ (X2)

\begin{tabular}{llllllllllll}
\hline Vegetation\bream & 60 & 55 & 50 & 45 & 40 & 35 & 30 & 25 & 20 & 15 & 10 \\
\hline 10 & $\mathrm{~T}(\mathrm{X} 2)$ & $\mathrm{T}$ & $\mathrm{T}$ & $\mathrm{T}$ & $\mathrm{T}$ & $\mathrm{T}$ & $\mathrm{T}$ & $\mathrm{T}$ & $\mathrm{T}$ & $\mathrm{T}$ & $26, \mathrm{~s}$ \\
15 & $\mathrm{~T}$ & $\mathrm{~T}$ & $\mathrm{~T}$ & $\mathrm{~T}$ & $\mathrm{~T}$ & $\mathrm{~T}$ & $\mathrm{~T}$ & $\mathrm{~T}$ & $\mathbf{7 8}$ & 23 & 16 \\
20 & $\mathrm{~T}$ & $\mathrm{~T}$ & $\mathrm{~T}$ & $\mathrm{~T}$ & $\mathrm{~T}$ & $\mathrm{~T}$ & $\mathbf{4 8}$ & 28 & 21 & 16 & 14 \\
25 & $\mathrm{~T}$ & $\mathbf{5 8}$ & $\mathbf{4 4}$ & 36 & 30 & 26 & 22 & 19 & 16 & 14 & 12 \\
30 & $26, \mathrm{~s}$ & 25 & 23 & 22 & 20 & 18 & 16 & 15 & 14 & 12 & $11, \mathrm{c}$ \\
\hline
\end{tabular}

$T$, the turbid state as result; $s$, (blue) single measures as restoration solutions; $c$, (red) particular examples for combined measure solutions. Bold numbers highlight very long restoration times 
Table 4 Possible restoration solutions to reach the clear state with single or combined short-term measures from different initial states. Initial states X1, X2, X2' and X3 are shown in Fig. 2

\begin{tabular}{|c|c|c|}
\hline Initial state & Single restoration measure & Combined restoration measures \\
\hline $\mathrm{X} 1$ & No restoration possible & $66 \%$ bream reduction AND $750 \%$ planting \\
\hline $\mathrm{X} 2$ (X1 + improved nutrient reduction) & $\begin{array}{l}80 \% \text { bream reduction OR } 200 \% \\
\text { planting }\end{array}$ & $\begin{array}{l}66 \% \text { bream reduction AND } \\
100 \% \text { planting }\end{array}$ \\
\hline $\begin{array}{l}\mathrm{X} 3 \text { (X1 + improved nutrient } \\
\text { reduction but } 20 \text { years delayed })\end{array}$ & $450 \%$ planting & $\begin{array}{l}(83 \% \text { bream reduction AND } \\
150 \% \text { planting) OR }(75 \% \text { bream } \\
\text { reduction AND } 200 \% \text { planting })\end{array}$ \\
\hline $\begin{array}{l}\mathrm{X} 2 \\
\text { mortality })\end{array}$ & $600 \%$ planting & $\begin{array}{l}83 \% \text { bream reduction AND } \\
250 \% \text { planting }\end{array}$ \\
\hline
\end{tabular}

\section{Discussion}

For assessing the sustainability of bistable ecosystems, the challenge moved from identifying the properties of bistability to investigating the short- and long-term effects of ecosystem management measures aimed at restoring the desired state. We extended a well-known minimal model for shallow lake regime shifts to investigate how interlinked dynamics of bream, pike and vegetation are affected by the combination of measures to restore the clear water state. A better understanding of transient dynamics between alternative stable states is particularly relevant to improve water quality in shallow temperate lakes (Martin et al. 2020; Capon et al. 2015).

\section{Model design with imperfect solutions}

While designing the new model, bistability in response to changes in nutrient concentration was the core pattern to reproduce, since earlier empirical and modelling studies emphasised its relevance in managing lakes (Scheffer and Van Nes 2007; Mooij et al. 2019). This guided our choice of parameter values and variations for a robustness analysis. The properties of bistability were highly sensitive towards changes in parameter variation (by $\pm 16 \%$ ). The investigated value range resulted in loss of bistability, bistability with hysteresis or bistability with imperfect bifurcation. This implies that vegetation properties, especially its growth rate and mortality induced by bream, can cause qualitatively different lake ecosystem dynamics. But, the validity of the model to better understand restoration dynamics is not necessarily improved by more precise ecological parameter values but by critically testing the implications from resulting stable state analyses. Thus, bifurcation analyses were used as a starting - rather than an endpoint— to design further model analyses and experiments. The choice of suitable parameter settings was finally a trade-off between expecting bistability with hysteresis and reproducing a sufficiently similar pattern of stable and unstable states compared with the original model, which left us to choose the case of imperfect bistability for further investigation of lake restoration.

\section{Lakes in transition can be restored to the clear state}

While most lake restoration studies focus on a single driver (nutrients, Hilt et al. (2018); planktivorous fish reduction, Bernes et al. (2015)) and immediate effects from response measures (Biggs et al. 2009), we shifted the focus to a combination of measures and their transient dynamics affecting the whole lakes system state. Studying transient dynamics of restoration from the turbid to the clear water state in shallow lakes allows insights on the interactions between different restoration measures with long-term lake dynamics. A combination of short-term measures, in this case planting of aquatic vegetation and bream reduction, rather than solely relying on nutrient reduction may be needed for reaching the clear state. This is in agreement with studies on other ecosystems, for instance coastal systems suffering from eutrophication (Duarte et al. 2009), in which the reduction of the bifurcation driver alone was not sufficient for restoration (Smith 2003). While the manipulation of the driver for bistability provides trivial solutions for long-term restoration (i.e. sufficient reduction of nutrients), we explored to which degrees combinations of short-term vegetation and bream manipulation enable a restoration for lakes in transition. We found in our model that the restoration time could be more drastically reduced by planting more vegetation than by reducing planktivorous fish (Table 4). This observation is supported by empirical studies investigating long-term effects from restoration measures (Søndergaard et al. 2007). But since bistability is not the only discontinuity known for shallow lakes (Scheffer and Van Nes 2007), further investigations of lake transitions from the turbid to the clear water state are needed. Shallow lake management is a suitable example to learn about managing regime shifts in general since eutrophication is a generalist driver linking multiple ecosystems, actors and beneficiaries on local and regional scales (Rocha et al. 2015). 


\section{Social-ecological transients to manage bistability}

Due to nonlinearity in many ecosystems, the proximity to the nearest stable state is insufficient to predict the time to reach it, let alone to assess the overall sustainability. Time to reach the stable state does not linearly correlate with the Euclidean distance between the initial condition and an attractor. That is why the investigation and differentiation between short- and long-term management measures and their effect on transient dynamics becomes crucial. At the same time, human responses to a deteriorating ecosystem state are highly unknown and seldom sufficiently pro-active to prevent a regime shift (Contamin and Ellison 2009; Biggs et al. 2009). One needs to account for diverse interests and directions to where humans influence the ecosystem, as for example also the turbid state of a lake can be reinforced by changing interests (Selkoe et al. 2015). This is where trajectory simulations enable a systematic evaluation of different initial states and exemplify transient dynamics under the assumption that the included interactions do not change over the simulated time span.

But further advancements in understanding human responses to regime shifts are necessary by making choices of adaptation and transformation during management more explicit in model simulations. While stable state analyses usually conclude with recommendations for preventing undesired tipping point transgressions, our analysis of transient dynamics exemplified how management measures can be effectively combined to reach an alternative state.

\section{Conclusions}

Our newly designed model increased the flexibility for testing and comparing suitable lake restoration measures in concert while keeping the parsimony and analytical strength of the original minimal model of lake bistability. The evaluation of transient dynamics resulting from short- or long-term measures provides new opportunities for understanding and identifying effective management of bistable systems. Our study enables an improved understanding of transient dynamics during regime shifts in shallow temperate lakes and serves as an example for how the transition towards a desired regime can be managed over time.

Funding information Open access funding provided by Stockholm University. RM was funded by the European Union's Horizon 2020 research and innovation programme (grant agreement No 642317 AQUACROSS) and by the project LimnoScenES (2017-2018 Belmont Forum and BiodivERsA joint call under the BiodivScen ERANet COFUND with funding from the Swedish Research Council FORMAS). SR and MS acknowledge funding by the European Research Council (ERC) under the European Union's Horizon 2020 research and innovation programme (grant agreement No 682472 MUSES).
Open Access This article is licensed under a Creative Commons Attribution 4.0 International License, which permits use, sharing, adaptation, distribution and reproduction in any medium or format, as long as you give appropriate credit to the original author(s) and the source, provide a link to the Creative Commons licence, and indicate if changes were made. The images or other third party material in this article are included in the article's Creative Commons licence, unless indicated otherwise in a credit line to the material. If material is not included in the article's Creative Commons licence and your intended use is not permitted by statutory regulation or exceeds the permitted use, you will need to obtain permission directly from the copyright holder. To view a copy of this licence, visit http://creativecommons. org/licenses/by/4.0/.

\section{References}

Ashwin P, Wieczorek S, Vitolo R, Cox P (2012) Tipping points in open systems: bifurcation, noise-induced and rate-dependent examples in the climate system. Philosophical Transactions of the Royal Society of London A: Mathematical, Physical and Engineering Sciences 370(1962):1166-1184. https://doi.org/10.1098/ rsta.2011.0306. http://rsta.royalsocietypublishing.org/content/ 370/1962/1166,00039

Beisner BE, Dent CL, Carpenter SR (2003) Variability of lakes on the landscape: roles of phosphorus, food webs, and dissolved organic carbon. Ecology 84(6):1563-1575. https://doi.org/10.1890/0012-9658(2003)0842.0.CO;2

Bernes C, Carpenter SR, Gårdmark A, Larsson P, Persson L, Skov C, Speed JD, Van Donk E (2015) What is the influence of a reduction of planktivorous and benthivorous fish on water quality in temperate eutrophic lakes? A systematic review. Environmental Evidence 4(1):1-28. https://doi.org/10.1186/s13750-015-0032-9

Biggs R, Carpenter SR, Brock WA (2009) Turning back from the brink: detecting an impending regime shift in time to avert it. Proceedings of the National Academy of Sciences of the United States of America 106(3):826-831. https://doi.org/10.1073/pnas.0811729106. http://www.ncbi.nlm. nih.gov/pmc/articles/PMC2630060/,00267

Biggs R, Peterson G, Rocha J (2018) The regime shifts database: a framework for analyzing regime shifts in social-ecological systems. Ecology and Society 23(3). https://doi.org/10.5751/ES-10264-230309. https://www. ecologyandsociety.org/vol23/iss3/art9/

Capon SJ, Lynch AJJ, Bond N, Chessman BC, Davis J, Davidson N, Finlayson M, Gell PA, Hohnberg D, Humphrey C, Kingsford RT, Nielsen D, Thomson JR, Ward K, Nally RM (2015) Regime shifts, thresholds and multiple stable states in freshwater ecosystems; a critical appraisal of the evidence. Science of The Total Environment 534:122130. https://doi.org/10.1016/j.scitotenv.2015.02.045. http://www. sciencedirect.com/science/article/pii/S0048969715001886

Carpenter SR, Bolgrienr D, Lathrop RC, Stow CA, Reed T (1998) Ecological and economic analysis of lake eutrophication by nonpoint pollution. Australian Journal of Ecology 23:68-79. https://doi.org/10.1111/j.1442-9993.1998.tb00706.x

Carpenter SR, Cole JJ, Hodgson JR, Kitchell JF, Pace ML, Bade D, Cottingham KL, Essington TE, Jeffrey N, Bade D, Cottingham KL, Essington TE, Houser JN, Schindler DE (2001) Trophic cascades, nutrients, and lake productivity: wholelake experiments. Ecological Monographs 71(2):163-186. https:// www.jstor.org/stable/2657215

Contamin R, Ellison AM (2009) Indicators of regime shifts in ecological systems: what do we need to know and when do 
we need to know it? Ecological Applications 19(3):799-816. https://doi.org/10.1890/08-0109.1

Dakos V, Carpenter SR, van Nes EH, Scheffer M (2014) Resilience indicators: prospects and limitations for early warnings of regime shifts. Philosophical Transactions of the Royal Society B: Biological Sciences 370(1659):2013026320130263. https://doi.org/10.1098/rstb.2013.0263. http://rstb. royalsocietypublishing.org/cgi/doi/10.1098/rstb.2013.0263

Duarte CM, Conley DJ, Carstensen J, Sánchez-Camacho M (2009) Return to neverland: shifting baselines affect eutrophication restoration targets. Estuaries and Coasts 32(1):29-36. https://doi.org/10.1007/s12237-008-9111-2

Galaz V (2005) Social-ecological resilience and social conflict: institutions and strategic adaptation in Swedish water management. Ambio 34(7):567-572. https://doi.org/10.1639/0044-7447(2005) 0342.0.CO;2,00057

Gunderson LH, Carpenter SR, Folke C, Olsson P, Peterson G (2006) Water RATs (resilience, adaptability, and transformability) in lake and wetland social-ecological systems. Ecology and Society 11(1)

Hilt S, Nuñez MMA, Bakker ES, Blindow I, Davidson TA, Gillefalk M, Hansson LA, Janse JH, Janssen ABG, Jeppesen E, Kabus T, Kelly A, Köhler J, Lester R (2018) Response of submerged macrophyte communities to external and internal restoration measures in North Temperate Shallow Lakes Frontiers in Plant Science 9(February). https://doi.org/10.3389/fpls.2018.00194

Hughes TP, Carpenter S, Rockström J, Scheffer M, Walker B (2013) Multiscale regime shifts and planetary boundaries. Trends in Ecology \& Evolution 28(7):389-95. https://doi.org/10.1016/j.tree.2013.05.019. http://www.ncbi.nlm. nih.gov/pubmed/23769417

Jeppesen E, Sndergaard M, Lauridsen TL, Kronvang B, Beklioglu M, Lammens E, Jensen HS, Kohler J, Ventela AM, Tarvainen M, Tatrai I (2007) Danish and other European experiences in managing shallow lakes. Lake and Reservoir Management 23(4):439-451. https://doi.org/10.1080/07438140709354029

Kininmonth S, Bergsten A, Bodin O (2015) Closing the collaborative gap: aligning social and ecological connectivity for better management of interconnected wetlands. Ambio 44:138-148. https://doi.org/10.1007/s13280-014-0605-9, 00018

Kuznetsov Y (2004) Elements of applied bifurcation theory, 3rd edn. Springer, Berlin

Lade SJ, Tavoni A, Levin SA, Schlüter M (2013) Regime shifts in a social-ecological system. Theoretical Ecology 6(3):359-372. https://doi.org/10.1007/s12080-013-0187-3

Lade SJ, Niiranen S, Hentati-Sundberg J, Blenckner T, Boonstra WJ, Orach K, Quaas MF, Österblom H, Schlüter M (2015) An empirical model of the Baltic Sea reveals the importance of social dynamics for ecological regime shifts. Proceedings of the National Academy of Sciences 112(AUGUST):201504954. https://doi.org/10.1073/pnas.1504954112

Martin R, Schlüter M (2015) Combining system dynamics and agentbased modeling to analyze social-ecological interactions-an example from modeling restoration of a shallow lake. Frontiers in Environmental Science 3. https://doi.org/10.3389/fenvs. 2015.00066. http://journal.frontiersin.org/Article/10.3389/fenvs. 2015.00066/abstract, 00001

Martin R, Schlüter M, Blenckner T (2020) The importance of transient social dynamics for restoring ecosystems beyond ecological tipping points. Proceedings of the National Academy of Sciences. https://doi.org/10.1073/pnas.1817154117. https://www. pnas.org/content/early/2020/01/17/1817154117

Mehner T, Arlinghaus R, Berg S, Dörner H, Jacobsen L, Kasprzak P, Koschel R, Schulze T, Skov C, Wolter C, Wysujack K (2004) How to link biomanipulation and sustainable fisheries management: a step-by-step guideline for lakes of the European temperate zone. Fisheries Management and Ecology 11(3-4):261275. https://doi.org/10.1111/j.1365-2400.2004.00401.x

Mooij WM, De Senerpont Domis LN, Janse JH (2009) Linking species- and ecosystem-level impacts of climate change in lakes with a complex and a minimal model. Ecological Modelling 220(21):3011-3020. https://doi.org/10.1016/j.ecolmodel. 2009.02.003. http://www.sciencedirect.com/science/article/pii/ S0304380009000921,00027

Mooij WM, Wijk DV, Beusen AHW, Brederveld RJ, Chang M, Cobben MMP, Deangelis DL, Downing AS, Green P, Gsell AS, Huttunen I, Janse JH, Janssen ABG, Hengeveld GM, Kong X, Kramer L, Kuiper JJ, Langan SJ, Nolet BA, Nuijten RJM, Strokal M, Troost TA, Dam AAV, Teurlincx S (2019) Modeling water quality in the anthropocene: directions for the next-generation aquatic ecosystem models. Current Opinion in Environmental Sustainability 36:85-95. https://doi.org/10.1016/j.cosust.2018.10.012

Pahl-Wostl C, Lebel L, Knieper C, Nikitina E (2012) From applying panaceas to mastering complexity: toward adaptive water governance in river basins. Environmental Science and Policy 23:24-34. https://doi.org/10.1016/j.envsci.2012.07.014

Rocha JC, Peterson GD, Biggs R (2015) Regime shifts in the anthropocene: drivers, risks, and resilience. PLOS ONE 10(8):e0134639. https://doi.org/10.1371/journal.pone.0134639. https://journals. plos.org/plosone/article?id=10.1371/journal.pone.0134639

Scheffer M (1989) Alternative stable states in eutrophic, shallow freshwater systems: a minimal model. Hydrobiological Bulletin 23(1):73-83. https://doi.org/10.1007/BF02286429. http:// link.springer.com/10.1007/BF02286429,00128

Scheffer M (1990) Multiplicity of stable states in freshwater systems. Hydrobiologia 200-201(1):475-486. https://doi.org/10.1007/ BF02530365. http://link.springer.com/10.1007/BF02530365, 00335

Scheffer M, Van Nes EH (2007) Shallow lakes theory revisited: various alternative regimes driven by climate, nutrients, depth and lake size. Hydrobiologia 584(1):455-466. https://doi.org/10.1007/s10750-007-0616-7

Scheffer M, Hosper SH, Meijer ML, Moss B, Jeppesen E (1993) Alternative equilibria in shallow lakes. Trends in Ecology \& Evolution 8(8):275-279. https://doi.org/10.1016/0169-5347(93) 90254-M. http://www.sciencedirect.com/science/article/pii/ $016953479390254 \mathrm{M}$

Scheffer M, Carpenter S, Foley JA, Folke C, Walker B (2001) Catastrophic shifts in ecosystems. Nature 413(6856):591596. https://doi.org/10.1038/35098000. http://www.nature.com/ doifinder/10.1038/35098000,04798

Selkoe KA, Blenckner T, Caldwell MR, Crowder LB, Erickson AL, Essington TE, Estes JA, Fujita RM, Halpern BS, Hunsicker ME, Kappel CV, Kelly RP, Kittinger JN, Levin PS, Lynham JM, Mach ME, Martone RG, Mease LA, Salomon AK, Samhouri JF, Scarborough C, Stier AC, White C, Zedler J (2015) Principles for managing marine ecosystems prone to tipping points. Ecosystem Health and Sustainability 1(5):art17. https://doi.org/10.1890/EHS14-0024.1

Smith V (2003) Eutrophication of freshwater and coastal marine ecosystems a global problem. Environmental Science and Pollution Research 10(2):126-139. https://doi.org/10.1065/espr2002. 12.142

Søndergaard M, Jeppesen E, Lauridsen TL, Skov C, Nes EHV, Roijackers R, Lammens E, Portielje R (2007) Lake restoration: successes, failures and long-term effects. Journal of Applied Ecology 44(6):1095-1105. https://doi.org/10.1111/j.1365-2664. 2007.01363.x. https://besjournals.onlinelibrary.wiley.com/doi/ abs/10.1111/j.1365-2664.2007.01363.x 
Wallin A, Zannakis M, Johansson LO, Molander S (2013) Influence of interventions and internal motivation on Swedish homeowners' change of on-site sewage systems. Resources, Conservation and Recycling 76:27-40. https://doi.org/10.1016/j.resconrec.
2013.04.004. http://www.sciencedirect.com/science/article/pii/ S0921344913000918,00005

Publisher's note Springer Nature remains neutral with regard to jurisdictional claims in published maps and institutional affiliations. 